\title{
Therapists' Contributions to the Alliance in Home-Based Family Treatment: The Role of Alliance Building Behaviors, Personality, and Clinical Experience
}

\author{
M. J. Welmers-van de Poll ${ }^{1,2}$ (I) G. J. J. M. Stams ${ }^{2}$ A. L. van den Akker $^{2} \cdot$ G. Overbeek ${ }^{2}$
}

Accepted: 6 July 2021 / Published online: 16 July 2021

(c) The Author(s) 2021

\begin{abstract}
Alliance is a robust contributor to the outcome of adult, youth, and family therapy, but little is known about therapists' contributions to the alliance in conjoint family treatment. We investigated the predictive value of therapists' personality, clinical experience and observed alliance building behaviors for mid-treatment alliance as reported by therapists and family members. Participants were 77 parents and 21 youth from 57 families receiving home-based family treatment from 33 therapists. Therapist openness to experience and agreeableness as well as therapists' in-session engagement and emotional connection behaviors predicted more positive therapists' and family members' reports of the alliance. Therapist neuroticism, extraversion and conscientiousness predicted more negative alliance-reports. In-session safety behaviors also predicted more negative alliance-reports, but this finding was only significant for therapists' and not family members' reports of the alliance. Clinical experience did not predict quality of alliances. We conclude that training and supervision of family therapists could benefit from focusing on emotional connection with and active engagement of family members in treatment, and from increasing self-awareness of the impact of their personality on alliances with family members.
\end{abstract}

Keywords Therapeutic alliance $\cdot$ Home-based family treatment $\cdot$ Alliance building behaviours $\cdot$ Therapist personality . Clinical experience

\section{Introduction}

Do some therapists have more success with their clients than others, and if so, what factors might explain this between-therapist difference? This question has received growing attention in psychotherapy research, and several studies indeed indicate substantial between-therapist variability in explaining treatment outcome (Crits-Cristoph, \& Mintz, 1991; Huppert et al., 2001; Zuroff et al., 2010). Previous studies have indicated that the extent to which they succeed in building alliances might be an important

M. J. Welmers-van de Poll

jm.welmers-vande.poll@windesheim.nl

1 Research Centre Youth, Windesheim University of Applied Sciences, Postbus 10090, Zwolle 8000 GB, The Netherlands

2 Research Institute of Child Development and Education, University of Amsterdam, Nieuwe Achtergracht 127, 1018 WS Amsterdam, The Netherlands factor in explaining variability in therapy success between therapists (Baldwin et al., 2007; Zuroff et al., 2010).

Alliance is generally defined as a professional relationship between a therapist and his or her client, consisting of an emotional bond and agreement on what goals and tasks should be central during treatment (Bordin, 1979; Elvins, \& Green, 2008). It has shown to be a significant contributor to psychotherapy outcome in adults, youth and families (Flückiger et al., 2018; Murphy \& Hutton 2018; Welmers-van de Poll et al., 2018). However, several studies have shown that therapists differ substantially in how much they succeed in building alliances with their clients (Dinger et al., 2008; Nissen-Lie et al., 2010). Thus, identifying therapist characteristics and behaviors that contribute to better alliances can be an important step towards a better understanding of between-therapist differences in treatment effectiveness. In the current paper, we aim to investigate the contribution of therapists' observed alliance building behaviors, personality, and years of clinical experience to the alliance in home-based family treatment. 


\section{Alliances in Family Treatment}

In conjoint family treatment, building alliances is complex for several reasons. First, the therapist simultaneously develops multiple alliances with different family members, who often have different or even conflicting needs and expectations of the treatment and the therapist. Second, family members observe and influence each other in their alliances with the therapist. Consequently, knowing they are observed by their partner, father, mother or children, family members might feel unsafe and reluctant to be open and collaborative with the therapist (Friedlander et al., 2006a). A final complexity in building alliances in family treatment is that treatment outcome is not only affected by family members' individual bond and collaboration with the therapist, but also by the extent to which family members form an alliance with each other, also referred to as the within-system alliance (Pinsof \& Catherall 1986), or shared sense of purpose within the family (Escudero et al., 2008; Friedlander et al., 2006a, 2006b; Isserlin, \& Couturier 2012).

In order to encompass these systemic complexities in a comprehensive model of the alliance in family therapy, Friedlander et al. (2006a) developed the System for Observing Family Therapy Alliances (SOFTA). This assessment system is based on a four domain model of the alliance, with two individual alliance domains reflecting (a) goal and task elements (Engagement in the Therapeutic Process), and (b) bond elements of the alliance (Emotional Connection to the Therapist), similar to Bordin's (1979) definition of the alliance for individual psychotherapy. The other two domains concern systemic aspects of the alliance unique to conjoint family treatment, that is, (c) Safety within the Therapeutic System, referring to family members experiencing the therapeutic environment as a safe place where they can take risks, be open and flexible, and handle family conflicts without risking harm, and (d) Shared Sense of Purpose within the Family, which is the agreement and cooperation between family members on shared goals (Friedlander et al., 2006a).

Several studies using the SOFTA to observe client behaviors indicate the importance of family members' sense of safety and their shared sense of purpose in promoting positive outcomes of family therapy (e.g. Escudero et al., 2008; Friedlander et al., 2008b; Isserlin \& Couturier, 2012; Sotero et al., 2018). Moreover, results of a recent meta-analysis on the association between alliance and outcome in couple and family therapy indicate that aspects of the alliance typical of systemic treatment, such as safety within the therapeutic system or the family's shared sense of purpose, are more predictive of outcome as compared to individual alliances with the therapist, even when these individual alliances of multiple family members are averaged to measure a family unit of alliance (Friedlander et al., 2018). This indicates that study findings on therapists' contributions to alliance in individual therapy cannot simply be generalized to family treatment, which emphasizes the importance of a systemic approach to the alliance in family therapy practice and research. However, studies examining therapists' contributions to the alliance in systemic family treatment are scarce (Sotero et al., 2017).

\section{Therapists' Alliance Building Behaviors}

Therapists' observed in-session behavior could be an important contributor to the alliance, as has been shown in several studies in individual youth therapy (Creed \& Kendall 2005; Fjermestad et al., 2020; Ovenstad et al., 2020). For conjoint family treatment however, studies on alliance building behaviors are scarce. Diamond et al. (1999) examined ten cases of adolescents in Multidimensional Family Therapy (MDFT) with initially poor alliances, and compared five improved cases with five unimproved cases. They found that in the improved cases, therapists more extensively presented themselves as the adolescent's ally, attended to the adolescent's experience, and formulated personally meaningful goals. In a comparable study on the alliance with adolescents in a Spanish setting of brief family therapy, Muñiz de la Peña et al. (2012) found that therapists showed significantly more competitive responding in poor alliance sessions. Competitive responding reflects two speakers' opposing views on who is in control in their relationship, resulting for example in not answering a question or interrupting the other speaker when he or she changes the conversation topic (Muñiz de la Peña et al., 2012). In the same study, cases with improved alliances showed a decrease in the therapist's competitive responding. Although both of these studies concerned family therapy, the studies did lack a systemic focus on the alliance, as they examined individual alliances with adolescents only.

Two other observational family therapy case studies examining alliances with the family describe how alliances improved when the therapist (a) explained a rationale for introducing new goals and tasks, (b) fostered emotional bonds with each family member, for example by reassuring and empathizing, (c) focused on family members' shared experiences and agreed upon goals, and (d) highly invested in family members' sense of safety during sessions (Escudero et al., 2012; Friedlander et al., 2014). Although providing valuable insight into good practices of alliance building and repairing in the context of family therapy, both case studies did not provide a statistical test of the association between alliance building behaviors and the alliance. Consequently, the effect of therapists' observed behaviors on alliances in family therapy remains unclear. 


\section{Personality and Clinical Experience}

Besides observable therapists' behaviors, relatively stable individual characteristics of the therapist might influence alliance processes. Two reviews of studies on therapists' contributions to the alliance in individual psychotherapy indicated that warmth, trustworthiness, flexibility, being interested, alert, relaxed, confident and respectful, are therapist characteristics associated with a stronger alliance (Ackerman \& Hilsenroth 2003), whereas being rigid, aloof, tense, uncertain, self-focused, and critical are associated with poorer alliances (Ackerman \& Hilsenroth 2001). However, few studies comprehensively examined associations between therapists' stable individual (personality) characteristics and alliance, while to our knowledge, no such studies exist for conjoint family treatment.

A well validated model that can be used to describe the therapist's personality characteristics, is The Five Factor Personality Model (Chapman et al., 2009; McCrae \& Costa 1987). This model distinguishes between neuroticism, extraversion, openness to experience, agreeableness, and conscientiousness as five basic personality domains (McCrae \& Costa 1987). Neuroticism is likely to negatively impact the therapist's ability to build strong alliances, as it refers to emotional instability and anxiety, lacking confidence, and being tense rather than relaxed (Hoekstra \& De Fruyt 2014). Neuroticism has been shown to negatively impact job performance more generally (Lado \& Alonso 2017), as well as the quality of intimate and social relationships (e.g. Karney \& Benjamin 1995; Lopes et al., 2003; Schaffhuser et al., 2014). In a recent study clients were asked to report on their ideal therapists' personality, and they particularly valued low neuroticism and high conscientiousness (Russell et al., 2020). Conscientiousness refers to being targeted, organized, ambitious, disciplined, and trustworthy (Hoekstra \& De Fruyt 2014), which positively impacts job performance (Barrick \& Mount, 1991; Lado \& Alonso 2017). The review by Ackerman and Hilsenroth (2003) indicated that therapists' trustworthiness was associated with stronger alliances, which supports the hypothesis that therapists' conscientiousness may positively impact the alliance. However, a recent study on personal style and personality dimensions of therapists providing individual, group or family therapy found that conscientiousness negatively impacted therapists' emotional closeness with their clients, possibly hampering the building of a strong alliance (Casari et al., 2019).

The remaining three domains of the Big Five Model all represent traits likely to positively impact the alliance. Extraverted individuals enjoy social interaction and tend to be warm (Hoekstra \& De Fruyt 2014), showing higher perceived quality of social relationships (Lopes et al., 2003). Agreeableness refers to being empathic, trusting, sincere, and caring (Hoekstra \& De Fruyt 2014), and is associated with having less conflicts in social relationships (Assendorpf \& Wilpers 1998). Finally, when therapists are more open to experience, they are more flexible, curious, and open to differing values of other people (Hoekstra \& De Fruyt 2014). This may help clients feel more accepted, which in turn can strengthen the therapeutic bond.

Chapman et al. (2009) used the Five Factor Personality (FFP) model to investigate the association between individual psychotherapy trainees' personality and alliance in a sample of 34 trainees and 64 clients. They found that three of the FFP domains were associated with the alliance. Highly neurotic therapist trainees received better alliance reports of their clients, but reported on poorer alliances themselves. Highly agreeable trainees also reported poorer alliances, but this was not the case in client reports. Finally, higher levels of openness of trainees were associated with less positive client-reports of the alliance. Chapman and others explained these somewhat surprising findings by the low levels of neuroticism and high levels of openness and agreeableness in their trainee sample as compared to national norms. Consequently, lower neuroticism and higher agreeableness and openness represented extreme levels of these traits, which may particularly explain their negative effect on the alliance. In the light of these findings, it is interesting to mention a study by Delgadillo et al. (2020), which showed that anxious and depressed clients individually treated by more agreeable and open psychologists had poorer treatment outcomes. Notably, therapists' means on these dimensions were exceeding national norms.

Although therapists' personality traits might help or hamper bonding and collaborating effectively with clients, clinical experience might help therapists to enhance those interpersonal skills that do not come naturally. Especially in family therapy, skills required for balancing multiple alliances and enhancing systemic aspects of the alliance are complex, and thus might benefit from extensive clinical experience. To our knowledge, there are no studies available examining the effect of the therapist's clinical experience on alliances in conjoint family treatment. Previous studies of other forms of therapy show mixed results. For example, Mallinckrodt and Nelson (1991) found that experienced post-graduate therapists had stronger alliances with their clients as compared to both novice and advanced psychotherapy trainees. Hersoug et al. (2009) found that in long-term psychotherapy more experienced therapists rated the alliance to be lower. However, in another study, with a larger sample of therapists, no effect was found for years of clinical experience on alliance (Dunkle \& Friedlander 1996). These equivocal results underline the relevance of further investigating the role of the therapists' clinical experience in building alliances. 


\section{Present Study}

This study aimed to examine the contribution of therapists' observed alliance building behaviors, personality, and clinical experience to the alliance in a home-based family treatment for youth problems. Empirical evidence suggests that the client's perspective on the alliance seems most predictive of outcome (Horvath et al., 2011). However, several studies support the predictive value of therapist reports as well (De Greef et al., 2018b; Flückiger et al., 2018; Zilcha-Mano et al., 2015). Also, it is the therapist who is responsible for managing the therapeutic process, including the process of building alliances and repairing problematic alliances if they occur (Hartmann et al., 2015). In this study we thus focused on predicting both family members' and therapists' experiences of the alliance. Because we were interested in alliance as a dynamic process that develops over time (Horvath, 2011; Welmers-van de Poll et al., 2018), we investigated mid-treatment alliance, taking into account the possible effects of early treatment therapist behavior and alliance.

We hypothesized that the therapist's personality, clinical experience, and observed alliance building behaviors would be significantly associated with mid-treatment alliance as reported by family members and therapists. More specifically, we expected that therapists' extraversion, openness to experience, and agreeableness would positively, and neuroticism would negatively predict quality of the alliance. As previous findings regarding conscientiousness (-related traits) as well as years of clinical experience were inconsistent, we did not formulate hypotheses for the direction of the association with the alliance for these characteristics. Finally, we expected that therapists' observed engagement, emotional connection, safety, and shared sense of purpose behaviors would predict more positive mid-treatment alliance reports.

\section{Methods}

\section{Participants and Treatment}

Participants were 77 parents ( $n=54$ (step)mothers, $n=23$ (step)fathers) and 21 children from 57 families. The mean age of the child for whom the treatment was indicated was $10(S D=4.4$, range $0-16.7)$. The mean age of the children participating in the study was 11.7 years $(S D=2.7$, range $5-16)$, and the mean age of parents was 39 years $(S D=7.8$, range 25-55). The study was carried out in the Netherlands, and most participants were born in the Netherlands. In 3 families, one or both parents were born in a western country other than the Netherlands, and in 4 families one or both parents were born in a non-western country. Participating families received home-based family treatment for youth problems, designated as Intensieve Pedagogische Thuishulp (IPT, Van der Steege, 2007). They were seen by 33 IPTworkers ( $12 \%$ male; $M$ age 42.7, $S D=9.3$ ), hereafter referred to as 'therapists'. All therapists had a social work related (post-) bachelor's degree and an average of 8.4 years of clinical experience $(S D=4.7)$. Each therapist saw 1-6 families $(M=1,73, S D=1,15)$.

Intensieve Pedagogische Thuishulp (IPT, Van der Steege, 2007) designates home based family treatment in the Netherlands for families dealing with complex child behavior and parenting problems. Most families experience problems in other domains as well, such as financial problems, parental psychopathology or lack of a supporting social network. An important treatment principle is that effective treatment for youth problems cannot be provided to a child isolated from parents and other family members and is best provided in the child's daily living environment (Van der Steege, 2007). Consequently, the treatment applies a systemic approach and is provided in the family's home. Furthermore, it is characterized by a solution-focused, empowering approach, focusing on improving parenting skills and enhancing social support. During treatment, an IPT-worker visits the family at their homes once or twice a week or once every two weeks, depending on the families' needs and stage of treatment. Families in this study received IPT for an average period of 50 weeks $(S D=30.2 ;$ Median $=45,5$; range 12-168), with the majority of families $(80 \%)$ receiving treatment with a length between 14 and 78 weeks.

\section{Measures}

\section{Working Alliance Inventory-Short Form (WAI-s)}

To assess the alliance, we used the Working Alliance Inventory, Short Form (WAI-s; Horvath \& Greenberg, 1989; Killian et al., 2017). The 12 items in this questionnaire (e.g. "My family counselor and I agree upon what I should do in order to improve the way things are going in my family" for the client version or "This client agrees upon what family members should do in order to improve the way things are going in the family" for the therapist version) are scored on a 5 point Likert-type scale ranging from 1 (never) to 5 (always). In the current sample, Cronbach's alpha for the therapists' version was 0.82 at $\mathrm{T} 1$ and 0.85 at $\mathrm{T} 2$, and for the clients' version 0.89 at $\mathrm{T} 1$ and 0.92 at $\mathrm{T} 2$.

\section{NEO-FFI}

We used the NEO Five Factor Inventory (NEO-FFI) to assess therapists' personality traits, which is a short version of the full length NEO-Personality Inventory, Revised (NEO-PI R; Costa, \& McCrae, 1992). The questionnaire contains 60 items scored on a 5-point Likert-type scale 
(strongly disagree-strongly agree). Subscales contain 12 items each and measure Neuroticism, Extraversion, Openness to Experience, Agreeableness, and Conscientiousness. Both the English and Dutch version show favorable validity and reliability (Hoekstra \& De Fruyt, 2014). In the current sample, Cronbach's alpha was 0.69 for Neuroticism and for Extraversion, 0.58 for Openness to experience, 0.74 for Agreeableness, and 0.60 for Conscientiousness.

\section{System for Observing Family Therapy Alliances (SOFTA-o) - Therapist version}

To assess therapists' alliance building behaviors we analyzed videotaped sessions using the therapist version of the SOFTA-o (Friedlander et al., 2006a). This instrument has been developed to asses four dimensions of alliance-related behavior from videotaped family or couple therapy sessions. Two dimensions reflect the individual alliance between a family member and the therapist similar to Bordin's (1979) classical definition of the alliance, i.e. Engagement in the Therapeutic Process, representing task and goal elements of the alliance, and Emotional Connection. The two other dimensions-Safety within the Therapeutic System, and Shared Sense of Purpose within the Family-reflect aspects of the alliance that are unique to conjoint family treatment. The therapist version, which we used for this study, measures the therapist's in-session contributions to these four dimensions.

When using the SOFTA-o, a trained coder observes a session and notes the frequency of specific positive and negative alliance-related behaviors along the four dimensions. Some examples for positive and negative (italized hereafter) behavioral indicators include "Therapist encourages client(s) to articulate their goals for therapy" or "Therapist argues with the client(s) about the nature, purpose, or value of therapy" for Engagement, "Therapist expresses interest in the client(s) apart from the therapeutic discussion at hand" or "Therapist has hostile, sarcastic, or critical interactions with the client(s)" for Emotional Connection, "Therapist acknowledges that therapy involves taking risks or discussing private matters" or "Therapist does not attend to overt expressions of client vulnerability (e.g. crying, defensiveness)" for Safety, and "Therapist encourages clients to ask each other for their perspective" or "Therapist fails to address one client's stated concerns by only discussing another client's concern" for Shared Sense of Purpose.

The Shared Sense of Purpose dimension can only be observed when two or more family members are in a session together, the other three dimensions can also be scored with only one family member present in a session. After observing the session, based on the frequency, intensity and clinical meaningfulness of the marked behaviors, coders assign global ratings on each dimension on a 7 point Likert scale ranging from -3 (extremely problematic) to +3 (extremely strong). For the purpose of this study, the SOFTA-o was translated from English to Dutch, following guidelines as prescribed by Van Widenfelt et al. (2005).

For coding the videotaped IPT-sessions with the SOFTAo, we used the training manual by Friedlander et al. (2005) as a guideline. The first author received training from Valentín Escudero, one of the developers of the SOFTA. After training and translation of the manual, first author coded 12 videotapes with at least two family members in the session to provide a coding standard for training other coders. Coding dilemmas from these 12 videotapes were discussed with Valentín Escudero. Next, 3 master students of Educational Sciences were trained, receiving $15 \mathrm{~h}$ of coder training over five weeks. They were introduced to the theoretical framework of the SOFTA, coding guidelines, practice material from the developers and Dutch practice material taken from the drama-series In Therapie (In Therapy). Trained coders independently coded at least 10 videotapes to increase their reliability as coders compared to the golden standard codings by first author and received feedback on each coding. As advised by Friedlander et al. (2005), training continued until coders differed no more than one point in their scale scores in $90 \%$ of the cases.

After their training, each coder rated a random selection of the videotapes. Coding dilemmas were discussed and difficult parts were consensus coded during meetings with the coding team every two weeks. In total, 90 sessions were independently coded after training. Of these sessions, 14 random selected sessions (16.6\%) were double coded by the first author, coders were blind to these double coded sessions. To assess interrater reliability, we calculated intraclass coefficients for the 14 double coded sessions using the single measures of a two-way mixed effect model based on absolute agreement (Koo \& Li, 2016). We first assessed reliability of the subscale scores as originally developed, that is, with a rating from -3 to +3 based on observed behaviors. Because these regular subscale scores had very little variance and because of this did not achieve sufficient interrater reliability, we chose to use a score for each subscale reflecting the number of observed positive behaviors per $60 \mathrm{~min}$. ICC's for these scores were 0.637 for Engagement, 0.551 for Emotional Connection, 0.558 for Safety, and -0.129 for Shared Sense of Purpose. According to Cicchetti (1994), ICC's are fair when $>0.4$, good $>0.6$ and excellent $>0.8$. The negative ICC for Shared Sense of Purpose could be explained by a low number of random selected sessions for double coding with two or more family members present in the session $(n=6)$ and by low variance (range $=0-3$ ). For this scale we therefore additionally analyzed percentage of agreement between coders and found that for $67.7 \%$ of the sessions there was $100 \%$ agreement on number of observed SSP behaviors, for $16.7 \%(n=1)$ of the sessions 
the difference between coders was 1 , and in the remaining $16.7 \%$ the difference was 2 . However, preliminary results showed that not only interrater reliability, but also variance was low for observed SSP behaviors. Therefore, we excluded this domain from our main analyses.

\section{Procedures}

Participating families were drawn from four IPT-teams of two Dutch youth care organizations. Each family that started treatment was informed about the research project by the IPT-worker or institution and received a letter with information. In one team, all IPT-workers directly asked their clients to participate. In the remaining three teams families were invited to participate by telephone by a research assistant. Participating family members of 12 years and older signed an informed consent letter, and the project was approved by the ethical review board of the university faculty where authors of the study were employed. All participating families received a $€ 10$ gift card and by draw, two families received a voucher for visiting a zoo or fun park of their own choice.

For each participating family two IPT-sessions at the family's home were videotaped. For T1-in the early treatment phase- the third session (and by exception the fourth or fifth) was filmed. We chose the third session because families were informed about the research and asked to consider participation in the first session. By choosing the third session they had some time to consider participation, but treatment was still in its starting phase, which lasts about six weeks (Van der Steege, 2007). The second video-observation (T2) was two months later, when treatment was in the phase of active change. Immediately after both video-recorded sessions, the therapist and participating family members were asked to independently fill out the Work Alliance Inventory (WAI). Children who were 8 years or older were asked to complete the Working Alliance Inventory (WAI). In some families, children above 8 did not want to participate in the research, and in other families the therapist saw one or two parents without a child for at least a part of the sessions, including the observed session. Therapists were asked to reflect on alliances with all family members actively involved in treatment, regardless of age. For 9 families there were no T2 measures available because the treatment had already ended $(n=3)$, or therapist or clients wished to end their participation after T1 because the situation had changed $(n=6)$, and for 1 family there was no T1 measure. Study dropouts were not excluded because this might have decreased the clinical representativeness of our study. We compared all measures at $\mathrm{T} 1$ as well as therapist personality measures and clinical experience for dropout and completer cases by performing a multilevel regression analysis of a dichotomous dropout variable at $\mathrm{T} 2$ on $\mathrm{T} 1$ client- and therapist reported alliance, T1 therapist observed alliance behaviors, therapist clinical experience and therapist neuroticism, extraversion, openness, agreeableness, and conscientiousness. We found no significant differences on any of these variables, except for therapists' observed safety behaviors $(\beta=1.231, p=0.001)$, indicating that therapists showed more safety behaviors at $\mathrm{T} 1$ in the dropout cases.

\section{Statistical Analyses}

First, we imputed missing values using expectation maximalization (Tabachnick, \& Fidell, 2013). After removing one case with $\mathrm{T} 1$ alliance measures as well as therapist variables missing, a MCAR test as proposed by Little (1988) indicated that missing values were completely at random $\left(\chi^{2}=415.076(370, N=98), p=0.053\right)$. Next, we tested for collinearity to enable a multivariate test of the relative importance of multiple independent variables by calculating a Variance Inflation Factor (VIF). All calculated VIF's were below 3 , indicating that there was no multicollinearity problem.

For our main analyses we used a two level model to account for dependency of data (Tabachnick \& Fidell, 2013), as family members (level 1) were nested within therapists (level 2). Level 1 concerns variance of alliance measures between family members within the family, while level 2 accounts for variance between families. Because of the shortterm longitudinal nature of the study (i.e. client- and therapist reports as well as therapist's alliance building behaviors were measured early and mid-treatment), we controlled for $\mathrm{T} 1$ alliance as well as $\mathrm{T} 1$ observed alliance building behaviors. We differentiated between parent-therapist and youththerapist alliance by adding a parent/youth variable to the model. Because some studies indicate that the strength of the alliance may differ between male and female therapists (e.g. Welmers- van de Poll et al., 2018), and that therapist age is associated both with years of clinical experience and observed interpersonal skills (Anderson et al., 2009), we also controlled for therapist age and gender. Within the twolevel model, we performed two stepwise multiple regression analyses to sequentially identify whether family role (parent vs. youth), therapist age and gender, clinical experience, personality traits, mid-treatment alliance building behaviors, early alliance, and early treatment alliance building behaviors (independent variables) were significantly associated with therapist reported mid-treatment alliance or with client reported mid-treatment alliance (dependent variables). 


\section{Results}

\section{Preliminary Analyses}

Table 1 shows the distribution of therapists' alliance building behaviors. Results indicate that therapists mainly invested in engagement and emotional connection, the two individual domains of the SOFTA model. Therapist behaviors contributing to safety and shared sense of purpose, the two systemic alliance domains of the SOFTA-model, were scarcely observed. As argued above, we excluded the shared sense of purpose domain from our main analyses.

Table 2 shows the distribution of therapists' scores on the NEO-FFI, as compared to a general sample of Dutch adults in the development sample of the measure (Hoekstra \& De Fruyt, 2014). Therapists in our sample reported notably higher levels of extraversion, agreeableness, and conscientiousness, lower levels of neuroticism, and similar levels of openness to experience as compared to the general Dutch sample.

Table 3 shows the distribution of WAI-therapist and WAIclient scores. Results indicate that family members' reports of the alliance were somewhat higher as compared to therapist reports. Differences between T1 and T2 were very small.

\section{Predictors of Therapist-reported Alliance}

We found that several variables significantly predicted therapist reports of mid-treatment alliance (Table 4). Family role predicted therapist reports of the alliance $(\beta=-0.156$, $p=0.003$ ), with therapists reporting stronger alliances with parents as compared to youth. As for demographic therapist features, only gender predicted therapist reports of the alliance, with female therapists reporting stronger alliances as compared to male therapists $(\beta=0.331, p<0.001)$. Therapist age did not predict therapist reports of the alliance.

Table 1 Therapists' alliance building behaviors

\begin{tabular}{|c|c|c|c|c|}
\hline & \multicolumn{2}{|l|}{$\mathrm{T} 1$} & \multicolumn{2}{|l|}{$\mathrm{T} 2$} \\
\hline & $n$ & Mean (SD) & $n$ & Mean (SD) \\
\hline $\begin{array}{l}\text { Engagement in the therapeutic } \\
\text { process }\end{array}$ & 54 & $12.4(5.6)$ & 45 & $12.3(6.1)$ \\
\hline Emotional connection & 54 & $14.5(10.0)$ & 45 & $14.4(8.5)$ \\
\hline $\begin{array}{l}\text { Safety within the therapeutic } \\
\text { system }\end{array}$ & 54 & $1.1(1.4)$ & 45 & $0.6(1.1)$ \\
\hline Shared sense of purpose & 30 & $0.5(0.8)$ & 20 & $0.4(0.7)$ \\
\hline
\end{tabular}

Scores on SOFTA-o therapist version, number of alliance building behaviors per $60 \mathrm{~min}$. $\mathrm{T} 1=$ starting phase of treatment; $\mathrm{T} 2=$ midtreatment. $n=$ number of families with a score of observed therapist behaviors on the designated SOFTA domain
Table 2 NEO-FFI scores

\begin{tabular}{lll}
\hline & $\begin{array}{l}\text { Therapist Sample } \\
(\mathrm{n}=29) \\
\text { Mean (SD) }\end{array}$ & $\begin{array}{l}\text { General Dutch } \\
\text { sample }^{1} \\
(\mathrm{n}=1715) \\
\text { Mean (SD) }\end{array}$ \\
\hline Neuroticism & $27.5(5.1)$ & $34.0(7.5)$ \\
Extraversion & $44.0(4.4)$ & $39.3(5.8)$ \\
Openness to Experience & $39.9(5.2)$ & $38.9(5.7)$ \\
Agreeableness & $48.8(4.1)$ & $41.1(5.6)$ \\
Conscientiousness & $46.7(4.0)$ & $43.4(5.7)$ \\
\hline
\end{tabular}

${ }^{1}$ General sample of Dutch adults in the development sample of the measure (Hoekstra \& De Fruyt, 2014)

As for therapist personality, all five personality domains were significant predictors of therapist-reported mid-treatment alliance, which was in line with our hypothesis. As expected, openness to experience $(\beta=0.517, p<0.001)$ and agreeableness $(\beta=0.306, p<0.01)$ were positively associated with therapists reports of the alliance, and neuroticism $(\beta=-0.472, p<0.001)$ was negatively associated. In contrast to our expectations, extraversion $(\beta=-0.304$, $p=0.001)$ was also negatively associated, as was conscientiousness ( $\beta=-0.230, p=0.006$ ), of which we had no previous expectations on the direction of the association. Our hypothesis on the contribution of therapists' clinical experience was not confirmed, as clinical experience was not significantly associated with therapist reports of midtreatment alliance.

As hypothesized, therapist alliance building behaviors predicted therapist reports of the alliance. Observed insession therapist engagement $(\beta=0.374, p<0.001)$ and emotional connection $(\beta=0.318, p<0.001)$ behaviors at $\mathrm{T} 2$ were positively associated with therapist reports of the alliance right after the observed session. In contrast to our hypothesis, observed in-session therapist safety behaviors $(\beta=-0.806, p<0.001)$ were negatively associated. Early therapist-reported alliance positively predicted therapists mid-treatment reports of the alliance $(\beta=0.398, p<0.001)$, whereas early treatment observed in-session alliance building behaviors did not. This indicates that there was no longitudinal contribution of observed early treatment in-session

Table 3 Scores on working alliance inventory

\begin{tabular}{|c|c|c|c|c|}
\hline & \multicolumn{2}{|c|}{$\mathrm{T} 1$} & \multicolumn{2}{|l|}{$\mathrm{T} 2$} \\
\hline & $n$ & Mean (SD) & $n$ & Mean (SD) \\
\hline Therapist reports & 87 & $3.9(0.4)$ & 77 & $4.0(0.4)$ \\
\hline Client reports & 86 & $4.2(0.6)$ & 69 & $4.3(0.6)$ \\
\hline
\end{tabular}

$\mathrm{T} 1=$ starting phase of treatment; $\mathrm{T} 2=$ mid-treatment. $n=$ number of individual family members with a therapist or client report on the alliance 
Table 4 Results of step wise multilevel regression modeling for predicting therapist-reported alliance at T2

\begin{tabular}{|c|c|c|c|c|c|c|}
\hline & $\begin{array}{l}\text { Model } 1 \\
\beta\end{array}$ & $\begin{array}{l}\text { Model } 2 \\
\beta\end{array}$ & $\begin{array}{l}\text { Model } 3 \\
\beta\end{array}$ & $\begin{array}{l}\text { Model } 4 \\
\beta\end{array}$ & $\begin{array}{l}\text { Model } 5 \\
\beta\end{array}$ & $\begin{array}{l}\text { Model } 6 \\
\beta\end{array}$ \\
\hline Family role $(0=$ parent, $1=$ youth $)$ & $-.282 * * *$ & $-.273 * * *$ & $-.292 * * *$ & $-.263 * * *$ & $-.175^{* *}$ & $-.156^{* *}$ \\
\hline Therapist age & & .143 & -.049 & -.063 & -.050 & -.069 \\
\hline Therapist gender $(0=$ male, $1=$ female $)$ & & $.442 * *$ & $.435^{* * *}$ & $.361 * * *$ & $.360 * * *$ & $.331 * * *$ \\
\hline Therapist experience & & & $.388 * *$ & .154 & -.024 & -.040 \\
\hline \multicolumn{7}{|l|}{ Therapist personality } \\
\hline Neuroticism & & & $-.245^{*}$ & $-.423 * * *$ & $-.458 * * *$ & $-.472 * * *$ \\
\hline Extraversion & & & -.109 & $-.239 *$ & $-.251 * *$ & $-.304 * *$ \\
\hline Openness & & & .161 & $.347 * *$ & $.462 * * *$ & $.517 * * *$ \\
\hline Agreeableness & & & .140 & .272 & $.243 * *$ & $.306 * *$ \\
\hline Conscientiousness & & & $-.297 * *$ & $-.287 * *$ & $-.265^{* * *}$ & $-.230 * *$ \\
\hline \multicolumn{7}{|l|}{ Therapist behavior $\mathrm{T} 2$} \\
\hline Engagement & & & & $.195^{+}$ & $.343 * * *$ & $.374 * * *$ \\
\hline Emotional Connection & & & & $.370 * * *$ & $.290 * * *$ & $.318 * * *$ \\
\hline Safety & & & & $-.551 * * *$ & $-.692 * * *$ & $-.806 * * *$ \\
\hline Alliance T1 & & & & & $.407 * * *$ & $.398 * * *$ \\
\hline \multicolumn{7}{|l|}{ Therapist behavior $\mathrm{T} 1$} \\
\hline Engagement & & & & & & .037 \\
\hline Emotional Connection & & & & & & -.019 \\
\hline Safety & & & & & & $-.130^{+}$ \\
\hline $\mathrm{X}^{2}(\Delta$ improvement compared to previous model $)$ & $15.975 * * *$ & 7.558 & $21.192 *$ & $28.616^{* *}$ & $27.711 * *$ & $-6.932 * * *$ \\
\hline $\mathrm{X}^{2}(\Delta$ improvement compared to null-model $)$ & $15.975 * * *$ & $23.515 * * *$ & $44.707 * * *$ & $73.323 * * *$ & $101.034 * * *$ & $94.102 * * *$ \\
\hline
\end{tabular}

$\mathrm{N}=57$ families, $n=77$ parents, $n=21$ youth, $\mathrm{N}=33$ therapists, ${ }^{+} p<.10,{ }^{*} p<.05$, ** $p<.01$, *** $p<.001$

alliance building behaviors to therapist reports of mid-treatment alliance.

\section{Predictors of Client-Reported Alliance}

As depicted in Table 5, several variables significantly predicted family members' reports of mid-treatment alliance. There were no significant differences in alliance reports between parents and youth. Therapist gender was the only demographic feature that significantly predicted family members' reports of the alliance, with higher alliance reports for female therapists as compared to male therapists $(\beta=0.404, p<0.001)$.

In line with our hypothesis, all five personality domains significantly predicted family members' reports of mid-treatment alliance, but directions of the association were only partly as hypothesized. As expected, openness to experience $(\beta=0.202, p=0.010)$ and agreeableness $(\beta=0.181$, $p=0.024$ ) were positively associated with family members' alliance reports, whereas Neuroticism was negatively associated $(\beta=-0.264, p<0.001)$. In contrast to our expectations, extraversion ( $\beta=-0.196, p=0.006$ ) was also negatively associated with family members' alliance reports, as was Conscientiousness $(\beta=-0.169, p=0.028)$, on which we had no previous expectation for the direction of the association.
These associations were all in the same direction as the associations with therapists' alliance reports. Our hypothesis on the contribution of therapists' clinical experience was not confirmed, as clinical experience was not significantly associated with therapist reports of mid-treatment alliance.

As hypothesized, therapist alliance building behaviors predicted family members' reports of the alliance: observed in-session therapist engagement $(\beta=0.305, p=0.001)$ and emotional connection $(\beta=0.237, p<0.001)$ behaviors at T2 were positively associated with family members' reports of the alliance right after the observed session. In contrast to our hypothesis, therapists' in-session safety behaviors were negatively but not significantly associated.

Early alliance as reported by family members positively predicted their mid-treatment reports of the alliance ( $\beta=0.464, p<0.001)$. Early treatment in-session therapist alliance building behaviors were not significantly associated, indicating that there was no longitudinal contribution of therapists' early treatment alliance building behaviors to family members' reports of mid-treatment alliance. 
Table 5 Results of step wise multi-level regression modeling for predicting client-reported alliance at T2

\begin{tabular}{|c|c|c|c|c|c|c|}
\hline & Model $1 \beta$ & Model $2 \beta$ & Model $3 \beta$ & Model $4 \beta$ & Model $5 \beta$ & Model $6 \beta$ \\
\hline Family role $(0=$ parent, $1=$ youth $)$ & -.134 & -.121 & $-.149 *$ & $-.154 *$ & -.062 & -.045 \\
\hline Therapist age & & $-.180 *$ & $-.361 * * *$ & $-.338 * *$ & $-.189^{*}$ & $-.161^{+}$ \\
\hline Therapist gender $(0=$ male, $1=$ female $)$ & & $.694 * * *$ & $.752 * * *$ & $.689 * * *$ & $.425 * * *$ & $.404 * * *$ \\
\hline Therapist experience & & & $.279 * *$ & .149 & .057 & .001 \\
\hline \multicolumn{7}{|l|}{ Therapist personality } \\
\hline Neuroticism & & & -.055 & $-.141^{+}$ & $-.243 * * *$ & $-.264 * * *$ \\
\hline Extraversion & & & $-.258 * *$ & $-.321 * *$ & $-.211 * *$ & $-.196 * *$ \\
\hline Openness & & & $.193^{*}$ & $.265 * *$ & $.207 * *$ & $.202 *$ \\
\hline Agreeableness & & & $.264 * *$ & $.304 * *$ & $.203 * *$ & $.181^{*}$ \\
\hline Conscientiousness & & & -.029 & -.026 & $-.128 * *$ & $-.169 *$ \\
\hline \multicolumn{7}{|l|}{ Therapist behavior $\mathrm{T} 2$} \\
\hline Engagement & & & & .110 & $.299 * * *$ & $.305^{* *}$ \\
\hline Emotional Connection & & & & $.226^{* *}$ & $.220 * * *$ & $.237 * * *$ \\
\hline Safety & & & & $-.219^{+}$ & $-.162^{+}$ & $-.198^{+}$ \\
\hline Alliance T1 & & & & & $.467 * * *$ & $.464 * * *$ \\
\hline \multicolumn{7}{|l|}{ Therapist behavior $\mathrm{T} 1$} \\
\hline Engagement & & & & & & .083 \\
\hline Emotional Connection & & & & & & .030 \\
\hline Safety & & & & & & .006 \\
\hline $\mathrm{X}^{2}(\Delta$ improvement compared to previous model $)$ & $-0.152 * * *$ & $41.961 * * *$ & 9.286 & 3.422 & $41.685^{* * *}$ & $-8.975 * * *$ \\
\hline $\mathrm{X}^{2}(\Delta$ improvement compared to null-model $)$ & $-0.152 * * *$ & $41.809 * * *$ & $51.095 * * *$ & $54.517 * * *$ & $96.202 * * *$ & $87.227 * * *$ \\
\hline
\end{tabular}

$\mathrm{N}=57$ families, $n=77$ parents, $n=21$ youth, $\mathrm{N}=33$ therapists, ${ }^{+} p<.10,{ }^{*} p<.05$, $* * p<.01, * * * p<.001$

\section{Discussion}

We examined the role of therapists' personality, years of clinical experience, and observed alliance building behaviors in predicting mid-treatment alliance in home-based family treatment for youth problems, controlling for family role (parent vs. youth), therapist age and gender and early treatment alliance. We found that therapist openness to experience and agreeableness as well as therapists' in-session engagement and emotional connection behaviors predicted more positive therapists' and family members' reports of the alliance. Therapist neuroticism, extraversion and conscientiousness predicted more negative alliance-reports. In-session safety behaviors also predicted more negative alliancereports, but this finding was only significant for therapists' and not family members' reports of the alliance. Clinical experience did not predict quality of alliances.

Our finding that therapists' personality traits predicted alliance was mostly in line with our hypotheses. As hypothesized, we found that both therapists and family members reported stronger alliances when therapists were more agreeable and open to experience. This is in contrast with findings of Chapman et al. (2009) in individual psychotherapy, indicating that more openness to experience was associated with less positive client-reports of the alliance, and that more agreeable trainees in their sample reported on weaker alliances themselves. The authors reason that, given the high levels of openness and agreeableness in their trainee sample, it seems plausible that only extreme levels of these traits did negatively influence the alliance. In our sample however, therapists also reported their levels of openness to be somewhat higher, and their levels of agreeableness a standard deviation higher than that of the general Dutch population. This indicates that even extremely agreeable and open therapists may be more successful in building alliances as reported by family members and by themselves. Our findings on neuroticism were also in line with our expectations, and in contrast with findings of Chapman et al. (2009) in their trainee sample. Our findings indicate that therapists who perceive themselves as emotionally stable rather than neurotic have stronger alliances as perceived by themselves and family members. This seems to apply even for extremely emotionally stable therapists, because in our sample therapists reported their levels of neuroticism to be almost a standard deviation lower than that of the general Dutch population.

We furthermore found that therapists' extraversion and conscientiousness negatively predicted both therapists' and family members' reports of the alliance. The negative contribution of conscientiousness could be explained by the fact that highly conscientious people are predominantly task-oriented, orderly, and less inclined to operate off the beaten track (Hoekstra \& De Fruyt 2014). This may hamper 
therapists' abilities to be flexible and accommodate treatment protocols to their clients' differing needs. Our finding on extraversion was surprising, given that extraverted individuals tend to be sociable, warm and optimistic. Our finding is also in contrast with previous findings of Chapman et al. (2009), indicating that extraversion did not impact the alliance. However, in our sample therapists rated their levels of extraversion almost a standard deviation higher compared to national norms. It is thus not precluded that average extraversion may help therapists in bonding with their clients, but that higher levels may become counterproductive. Perhaps a highly extraverted therapist, who is likely to be very talkative, energetic, and optimistic, can be overwhelming and difficult to relate to for clients, who may feel rather depressed and pessimistic when receiving help for serious child and parenting problems. Another explanation that highly extraverted therapists were found to have less strong alliances with families in our sample, could lie in cultural background: perhaps extraversion is valued less in some cultures than in others (Hofstee et al., 1997).

We found no contribution of therapists' years of clinical experience to alliance. Initially, there was a significant association when clinical experience was first added to both our regression models, but it disappeared when we added alliance building behaviors to these models. This indicates that any assumed contribution of the therapists' clinical experience to alliances should rather be explained by what therapists' do during a session to strengthen the alliance. It could thus be reasoned that therapists' clinical experience contributes to their in-session alliance building behavior. Indeed, Raytek et al. (1999) found that in a conjoint couple alcoholism treatment more experienced therapists showed more alliance fostering behaviors and less nonfacilitative behaviors as compared to less experienced therapists. A previous study on therapists' contributions to alliance in home-based family treatment showed that therapists' clinical experience positively impacted only early treatment engagement behaviors (Welmers-van de Poll \& Stams, 2019). There was no effect of clinical experience on any observed midtreatment behaviors or for early treatment emotional connection and safety behaviors. Note that in the present study we only examined therapists' and family members' ratings of their individual alliances, since there were no therapistor self-reports on safety or shared sense of purpose. Future research could investigate whether perhaps the more complex aspects of alliance in conjoint treatment, such as creating a safe therapeutic environment for each family member or enhancing the within-family alliance, are more affected by the therapists' clinical experience.

Regarding therapists' observed in-session alliance building behaviors in the present study, we found that observed engagement and emotional connection behaviors predicted both their own and family members' reports of the alliance, which was in line with our hypotheses. In a previous study investigating observations of client behaviors in relation to self- and therapist-reports of alliance, engagement and emotional connection behaviors of family members were also positively associated with their self-reports, but not with therapist-reports (Friedlander et al., 2006b). Our finding indicates that when the therapist actively engages family members in the treatment process and connects with them at an emotional level, both the therapist and the family evaluate the alliance as more positive.

In contrast to our expectations, therapists' and family members' reports of the alliance were negatively associated with therapists' in-session safety behaviors, such as providing structure and guidelines for safety and confidentiality or actively protecting one family member from another. This is remarkable given the low occurrence of these behaviors in the included observed sessions. The negative direction of the association was replicated in predicting family members' reports of the alliance, although this association just failed to reach significance. Our finding could indicate that therapists' safety interventions have a negative effect on the alliance, even when applied scarcely. However, two previous studies including observations of family members' in-session safety behaviors indicate that a sense of safety in the therapeutic context does promote positive outcome of systemic family treatment (Friedlander et al., 2008b; Sotero et al., 2018). An alternative explanation for our finding may be that therapists increase their investment in safety when they perceive their alliance with family members as less favorable. This presumed mechanism is in line with Escudero and Friedlander's (2017) proposed strategy for navigating alliances in challenging contexts of family treatment. They argue that a sense of safety among family members who are in treatment together is an essential precondition for facilitating strong bonds between the therapist and each family member, as well as for facilitating family members' engagement in the treatment process and their shared sense of purpose.

The fact that our findings on the therapists' personality and alliance building behaviors in predicting mid-treatment alliance were significant even after controlling for early treatment alliance reports underlines the robustness of our findings. It indicates that regardless of fluctuations in alliance from early to mid-treatment, alliances are still relatively stronger when therapists are more agreeable, open and emotionally stable, and when they emotionally connect with family members and actively engage them in the treatment process. We also controlled for early treatment alliance building behaviors, but found no longitudinal contribution of therapist behaviors during early treatment to mid-treatment alliance reports of therapists and family members. This indicates that what therapists do during a specific session to strengthen the alliance only impacts therapists' 
and family members' evaluation of the alliance shortly after this session.

Although not a specific focus of our study, it was interesting to find that therapists mainly invested in individual alliances with family members, but scarcely in systemic aspects of the alliance (safety and shared sense of purpose). This finding is in line with indications of Friedlander et al. (2019) that even highly experienced family therapists tend to focus mainly on individual alliances with family members, overlooking the importance of systemic aspects of the alliance, such as in-session safety and a shared purpose among family members. Although in our study more safety-promoting behaviors of the therapist were associated with less favorable therapist-reports of the alliance, several studies on alliance in family therapy indicate that family members' in-session experience of safety (Friedlander et al., 2008b; Sotero et al., 2018) as well the family's shared purpose (Escudero et al., 2008; Friedlander et al., 2008b; Sotero et al., 2018) promote positive treatment outcomes of systemic family treatment. Recent meta-analytic findings show that these systemic aspects of the alliance seem to be even more vital for positive treatment outcomes than family members' individual alliances with the therapist (Friedlander et al., 2018). These combined study findings emphasize the need for a systemic focus on the alliance in training and supervision of family therapists.

This study has some limitations. First, because the subscale scores as originally developed for the SOFTA resulted in little variance and insufficient interrater reliability, we instead used behavioral frequencies for each SOFTA alliance domain, with moderate interrater reliability. This means we only investigated the quantitative contribution of positive alliance building behaviors, whereas negative behaviors as well as clinical importance and context of certain therapist behaviors can also impact the alliance (e.g. Ackerman \& Hilsenroth, 2001; Boardman et al., 2006; Friedlander et al., 2006a; Muñiz de la Peña et al., 2012).

Second, despite the vital importance of systemic aspects of the alliance in conjoint family treatment, such as a shared purpose among family members and a sense of safety during treatment (Friedlander et al., 2019), we had no data on family members' and therapists' experience of these systemic aspects. This was due to the fact that we only had self- and therapist reported data from the WAI measure, designed for individual therapy, and the fact that measures of therapists' observed shared sense of purpose behaviors had to be excluded from this study due to insufficient reliability. Regarding differences between family members in their alliance with the therapist - another systemic complexity in building alliances in family treatment- the number of included youth in our sample did not provide sufficient statistic power to differentiate between therapists' contributions to alliances with parents and alliances with youth. We did however include multiple family members as informant of the alliance, controlled for family role (parent vs. youth) in our models, and included observations of therapists' safety behaviors, and thus to some extent accounted for systemic alliance complexity.

A final limitation is that we only investigated therapists' unilateral contributions to the alliance, and not the interaction between therapists' and family members' contributions. This might imply that there is such a thing as a universal set of therapist characteristics that are best for every client or family. However, not only differences between therapists in their alliances with clients impact treatment outcome, alliance differences between clients treated by the same therapist can also be of substantial influence (Baldwin \& Imel 2013). Future research could benefit from explaining why a given therapist has above average alliances with some families and family members, but below average alliances with other families and family members. This involves investigating families' and family members' characteristics contributing to the alliance (e.g. De Greef et al, 2018a; Sotero et al., 2017), as well as the effect of interaction or 'match' between therapist and family members' characteristics and behaviors (e.g. Friedlander et al., 2008a).

Despite its limitations, to our knowledge our study was the first to investigate therapists' contributions to the alliance in family treatment including therapist personality and years of clinical experience. Although therapists' observed in-session alliance building behaviors have been studied before in family therapy (Diamond et al., 1999; Escudero et al., 2012; Friedlander et al., 2014; Muñiz de la Peña et al., 2012), our study adds to this body of knowledge by studying a larger sample, and providing empirical evidence for the association between therapist behaviors and family members' as well therapists' reports of the alliance. The multi-informant character strengthens the robustness of our study findings. Another strength is the (short-term) longitudinal design, investigating the alliance as a process that evolves during treatment rather than as a static phenomenon.

Considering the small body of research on therapists' characteristics contributing to the alliance in family treatment, a replication of our study findings is vital to build a stronger evidence base. Future studies could benefit from investigating family effects as well as effects of interaction between therapist and family members' characteristics or behaviors in relation to the alliance. Our finding that safetypromoting behaviors of the therapist were associated with less favorable therapist-reports of the alliance seems somewhat contradictory to previous findings on family members' in-session safety in relation to treatment outcome: further research on the role of safety during treatment may particularly benefit from studying interactions between therapist and client behaviors. Finally, given the vital importance of alliance aspects typical of systemic treatment, an important 
next step is to investigate therapists' contributions predicting these systemic aspects. This includes investigating therapists' contributions to the family's shared sense of purpose, their sense of safety and problematic differences between family members in their alliance with the therapist.

For clinical practice, our results implicate that training and supervision of family therapists could benefit from focusing on behaviors that enhance family members' engagement in treatment and emotional connection to the therapist. More occurrences of these behaviors in treatment sessions may positively influence family members' alliances with the therapist, which in turn is likely to improve treatment outcomes. Additionally, training and supervision could be more effective when accommodated to the trainees' personality profiles. Increasing trainees' self-awareness and monitoring of the way their neurotic, extraverted, or conscientious tendencies become too manifest in expressed behavior during sessions might enhance the ability of family therapists in building strong alliances with family members in order to increase treatment effectiveness.

Acknowledgements The authors would like to thank participating family members and therapists for sharing their in-session work and experience, and Nina van Basten, Muriël Dijkman, and Naoual el Kabdi for their valuable coding work.

Funding Marianne Welmers receives a $\mathrm{PhD}$ scholarship granted by The Netherlands Organisation for Scientific Research (NWO, Grant Number 023.006.088). This paper is part of the $\mathrm{PhD}$ program. Geertjan Overbeek was supported by a grant (016.vici. 185.063) from the NWO during the preparation of this manuscript. NWO had no role in the study design, collection, analysis or interpretation of the data, writing the manuscript, or the decision to submit the paper for publication.

\section{Declarations}

Conflict of interest All authors declare that they have no conflict of interest.

Open Access This article is licensed under a Creative Commons Attribution 4.0 International License, which permits use, sharing, adaptation, distribution and reproduction in any medium or format, as long as you give appropriate credit to the original author(s) and the source, provide a link to the Creative Commons licence, and indicate if changes were made. The images or other third party material in this article are included in the article's Creative Commons licence, unless indicated otherwise in a credit line to the material. If material is not included in the article's Creative Commons licence and your intended use is not permitted by statutory regulation or exceeds the permitted use, you will need to obtain permission directly from the copyright holder. To view a copy of this licence, visit http://creativecommons.org/licenses/by/4.0/.

\section{References}

Ackerman, S. J., \& Hilsenroth, M. J. (2001). A review of therapist characteristics and techniques negatively impacting the therapeutic alliance. Psychotherapy, 39(2), 171-185. https://doi.org/10.1037/ 0033-3204.38.2.171

Ackerman, S. J., \& Hilsenroth, M. J. (2003). A review of therapist characteristics and techniques positively impacting the therapeutic alliance. Clinical Psychology Review, 23, 1-33.

Anderson, T. A., Ogles, B. M., Patterson, C. L., Lambert, M. J., \& Vermeersch, D. A. (2009). Therapist effects: Facilitative interpersonal skills as a predictor of therapist success. Journal of Clinical Psychology, 65(7), 755-768. https://doi.org/10.1002/jclp.20583

Assendorpf, J. B., \& Wilpers, S. (1998). Personality effects on social relationships. Journal of Personality and Social Psychology, 74(6), 1531-1544. https://doi.org/10.1037/0022-3514.74.6.1531

Baldwin, S. A., \& Imel, Z. E. (2013). Therapist Effects: Findings and Methods. In M. J. Lambert (Ed.), Bergin and Garfield's Handbook of Psychotherapy and Behavior Change. John Wiley \& Sons, Inc.

Baldwin, S. A., Wampold, B. E., \& Imel, Z. E. (2007). Untangling the alliance-outcome correlation: Exploring the relative importance of therapist and patient variability in the alliance. Journal of Consulting and Clinical Psychology, 75(6), 842-852. https:// doi.org/10.1037/0022-006X75.6.842

Barrick, M. R., \& Mount, M. K. (1991). The big five personality dimensions and job performance: A meta-analysis. Personnel Psychology, 44, 1-27. https://doi.org/10.1111/j.1744-6570. 1991.tb00688.x

Boardman, T., Catley, D., Grobe, J. E., Little, T. D., \& Ahluwalia, J. S. (2006). Using motivational interviewing with smokers: Do therapist behaviors relate to engagement and therapeutic alliance? Journal of Substance Abuse Treatment, 31, 329-339. https://doi.org/10.1016/j.jsat.2006.05.006

Bordin, E. S. (1979). The generalizability of the psychoanalytic concept of the working alliance. Psychotherapy: Theory, Research \& Practice, 16(3), 252-260.

Casari, L. M., Ison, M. S., \& Gomez, B. M. M. (2019). Personal style of the therapist and personality dimension in a sample of Argentinian therapists. Research in Psychotherapy: Psychopathology, Process and Outcome, 22, 292-307. https://doi.org/10. 4081/ripppo.2019.362

Chapman, B. P., Talbot, N., Tatman, A. W., \& Britton, P. C. (2009). Personality traits and the working alliance in psychotherapy trainees: An organizing role for the five factor model? Journal of Social and Clinical Psychology, 28(5), 577-596. https://doi. org/10.1521/jscp.2009.28.5.577

Cicchetti, D. V. (1994). Guidelines, criteria, and rules of thumb for evaluating normed and standardized assessment instruments in psychology. Psychological Assessment, 6(4), 284-290. https:// doi.org/10.1037/1040-3590.6.284

Costa, P. T., Jr., \& McCrae, R. R. (1992). Revised NEO personality inventory (NEO-PI-R) and the five facor inventory (NEO-FFI): professional manual. Psychological Assessment Resources Inc.

Creed, T. A., \& Kendall, P. C. (2005). Therapist alliance-building behavior within a cognitive-behavioral treatment for anxiety in youth. Journal of Consulting and Clinical Psychology, 73(3), 498-505. https://doi.org/10.1037/0022-006X.73.3.498

De Greef, M., McLeod, B. D., Scholte, R. H. J., Delsing, M. J. M., Pijnenburg, H. M., \& Van Hattum, M. J. C. (2018b). Predictive value of parent-professional alliance for outcomes of homebased parenting support. Child \& Youth Care Forum, 47, 881895. https://doi.org/10.1007/s10566-018-9467-9

De Greef, M., Van Hattum, M. J. C., Granger, K. L., McLeod, B. D., Pijnenburg, H. M., \& Scholte, R. H. J. (2018a). Predictors of parent-professional alliance in home-based parenting support. Children and Youth Services Review, 89, 171-178. https://doi. org/10.1016/j.childyouth.2018.04.028

Delgadillo, J., Branson, A., Kellett, S., Myles-Hooton, P., Hardy, G. E., \& Shafran, R. (2020). Therapist personality traits as predictors 
of psychological treatment outcomes. Psychotherapy Research, 30(7), 857-870. https://doi.org/10.1080/10503307.2020.1731927

Diamond, G. M., Hogue, A., Liddle, H. A., \& Dakof, G. A. (1999). Alliance-building interventions with adolescents in family therapy: A process study. Psychotherapy, 36(4), 355-368. https://doi. org $/ 10.1037 / \mathrm{h} 0087729$

Dinger, U., Strack, M., Leichsenring, F., Wilmers, F., \& Schauenburg, H. (2008). Therapist Effects on outcome and alliance in inpatient psychotherapy. Journal of Clinical Psychology, 64(3), 344-354. https://doi.org/10.1002/jclp.20443

Elvins, R., \& Green, J. (2008). The conceptualization and measurement of therapeutic alliance: An empirical review. Clinical Psychology Review, 28, 1167-1187. https://doi.org/10.1016/j/cpr.2008.04.002

Escudero, V., Boogmans, E., Loots, G., \& Friedlander, M. L. (2012). Alliance rupture and repair in conjoint family therapy: An exploratory study. Psychotherapy, 49(1), 26-37. https://doi.org/10.1037/ a0026747

Escudero, V., \& Friedlander, M. L. (2017). Therapeutic Alliances with Families. Empowering Clients in Challenging Cases. Spinger Nature.

Escudero, V., Friedlander, M. L., Varela, N., \& Abascal, A. (2008). Observing the therapeutic alliance in family therapy: Associations with participants' perceptions and therapeutic outcomes. Journal of Family Therapy, 30(2), 194-214. https://doi.org/10.1111/j. 1467-6427.2008.00425.x

Fjermestad, K. W., Føreland, Ø., Oppedal, S. B., Sørensen, Y. H., Vognild, R. G., Öst, L., Bjaastad, J. F., Shirk, S. S., \& Wergeland, G. J. (2020). Therapist alliance-building behaviors, alliance, and outcomes in cognitive behavioral treatment for youth anxiety disorders. Journal of Clinical Child \& Adolescent Psychology. https://doi.org/10.1080/15374416.2019.1683850

Flückiger, C., Del Re, A. C., Wampold, B. E., \& Horvath, A. O. (2018). The alliance in adult psychotherapy: A meta-analytic synthesis. Psychotherapy, 55(4), 316-340. https://doi.org/10.1037/pst00 00172

Friedlander, M. L., Escudero, V., \& Heatherington, L. (2006a). Therapeutic Alliances in Couple and Family Therapy. An Empirically Informed Guide to Practice. American Psychological Association.

Friedlander, M.L., Escudero, V., Heatherington, L., Deihl, L., Field, N., Lehman, P., McKee, M., \& Cutting, M. (2005). System for Observing Family Therapy Alliances (SOFTA-o). Training Manual. Downloaded from http://softa-soatif.hl17.dinaserver.com/ wp-content/uploads/2014/06/Softa_CodingManual.pdf

Friedlander, M. L., Escudero, V., Horvath, A. O., \& Heatherington, L. (2006b). System for observing family therapy alliances: A tool for research and practice. Journal of Counseling Psychology, 53(2), 214-224. https://doi.org/10.1037/0022-0167.53.2.214

Friedlander, M. L., Escudero, V., Welmers-van de Poll, M. J., \& Heatherington, L. (2018). Meta-analysis of the alliance-outcome relation in couple and family therapy. Psychotherapy, 55(4), 356-371. https://doi.org/10.1037/pst0000161

Friedlander, M. L., Escudero, V., Welmers-van de Poll, M. J., \& Heatherington, L. (2019). Alliances in Couple- and Family Therapy. In J. C. Norcross \& M. J. Lambert (Eds.), Psychotherapy Relationships that Work III. Oxford University Press.

Friedlander, M. L., Lambert, J. E., Escudero, V., \& Cragun, C. (2008). How do therapists enhance family alliances? Sequential analyses of therapist-client behavior in two contrasting cases. Psychotherapy Research, Practice, Training, 45(1), 75-87. https://doi.org/ 10.1037/0033-3204.45.1.75

Friedlander, M. L., Lambert, J. E., \& Muñiz de la Peña, C. (2008b). A step toward disentangling the alliance/improvement cycle in family therapy. Journal of Counseling Psychology, 55, 118-124. https://doi.org/10.1037/0022-0167.55.1.118
Friedlander, M. L., Lee, H., Shaffer, K. S., \& Cabrera, P. (2014). Negotiating therapeutic alliances with a family at impasse. Psychotherapy, 51(1), 41-52. https://doi.org/10.1037/a0032524

Hartmann, A., Joos, A., Orlinsky, D. E., \& Zeekc, A. (2015). Accuracy of therapist perceptions of patients' alliance: Exploring the divergence. Psychotherapy Research, 25(4), 408-419. https://doi.org/ 10.1080/10503307.2014.927601

Hersoug, A. G., Høglend, P., Havik, O., von der Lippe, A., \& Monsen, J. (2009). Therapist characteristics influencing the quality of alliance in long-term psychotherapy. Clinical Psychology and Psychotherapy, 16, 100-110. https://doi.org/10.1002/cpp.605

Hoekstra, H., \& De Fruyt, F. (2014). NEO-PI-3 Persoonlijkheidsvragenlijst. Handleiding. Hogrefe.

Hofstee, W. K., Kiers, H. A. L., De Raad, B., Goldberg, L. R., \& Ostendorf, F. (1997). A comparison of big-five structures of personality traits in Dutch, English, and German. European Journal of Personality, 11(1), 15-31.

Horvath, A. O., Del Re, A. C., Flückiger, C., \& Symonds, D. (2011). Alliance in individual psychotherapy. Psychotherapy, 48(1), 9-16. https://doi.org/10.1093/acprof:oso/9780199737208.003.0002

Huppert, J. D., Bufka, L. F., Barlow, D. H., Gorman, J. M., Shear, M. K., \& Woods, S. W. (2001). Therapists, therapist variables, and cognitive-behavioral therapy outcome in a multicenter trial for panic disorder. Journal of Consulting and Clinical Psychology, 69(5), 747-755. https://doi.org/10.1037/0022-006X.69.5.747

Isserlin, L., \& Couturier, J. (2012). Therapeutic alliance and familybased treatment for adolescents with anorexia nervosa. Psychotherapy, 49(1), 46-51. https://doi.org/10.1037/a0023905

Karney, B. R., \& Thomas, B. N. (1995). The longitudinal course of marital quality and stability: A review of theory, method, and research. Psychological Bulletin, 118(1), 3-34.

Killian, M., Forrester, D., Westlake, D., \& Antonopoulou, P. (2017). Validity of the working alliance inventory within child protection services. Research on Social Work Practice, 27(6), 704-715. https://doi.org/10.1177/1049731515596816

Koo, T. K., \& Li, M. Y. (2016). A guideline of selecting and reporting intraclass correlation coefficients for reliability research. Journal of Chirapractic Medicine, 15, 155-163. https://doi.org/10.1016/j. jcm.2016.02.012

Lado, M., \& Alonso, P. (2017). The five-factor model and job performance in low complexity jobs: A quantitative synthesis. Revista De Psicología Del Trabajo y De Las Organizaciones, 33(3), 175182. https://doi.org/10.1016/j.rpto.2017.07.004

Little, R. J. A. (1988). A test of missing completely at random for multivariate data with missing values. Journal of the American Statistical Association, 83(404), 1198-1202. https://doi.org/10. 1080/01621459.1988.10478722

Lopes, P. N., Salovey, P., \& Straus, R. (2003). Emotional intelligence, personality, and the perceived quality of social relationships. Personality and Individual Differences, 35(3), 641-658. https://doi. org/10.1016/S0191-8869(02)00242-8

Mallinkcrodt, B., \& Nelson, M. L. (1991). Counselor training level and the formation of the psychotherapeutic working alliance. Journal of Counseling Psychology, 38(2), 133-138. https://doi.org/10. 1037/0022-0167.38.133

McCrae, R. R., \& Costa, P. T. (1987). Validation of the five-factor model of personality across instruments and observers. Journal of Personality and Social Psychology, 52(1), 81-90. https://doi. org/10.1037/0022-3514.52.81

Muñiz de la Peña, C., Friedlander, M. L., Escudero, V., \& Heatherington, L. (2012). How do therapists ally with adolescents in family therapy? An examination of relational control communication in early sessions. Journal of Counseling Psychology, 59(3), 339351. https://doi.org/10.1037/a0028063 
Murphy, R., \& Hutton, P. (2018). Practitioner Review: Therapist variability, patient-reported therapeutic alliance, and clinical outcomes in adolescents undergoing mental health treatment-a systematic review and meta-analysis. Journal of Child Psychology and Psychiatry, 59, 5-19. https://doi.org/10.1111/jcpp.12767

Nissen-Lie, H. A., Monsen, J. T., \& Rønnestad, M. H. (2010). Therapist predictors of early patient-rated working alliance: A multilevel approach. Psychotherapy Research, 20(6), 627-646. https://doi. org/10.1080/10503307.2010.497633

Ovenstad, K. S., Ormhaug, S. M., Shirk, S. R., \& Jensen, T. K. (2020). Therapists' behaviors and youths' therapeutic alliance during trauma-focused cognitive behavioral therapy. Journal of Consulting and Clinical Psychology, 88(4), 350-361. https://doi.org/10. 1037/ccp0000465

Pinsof, W. B., \& Catherall, D. (1986). The integrative psychotherapy alliance: Family, couple and individual therapy scales. Journal of Marital and Family Therapy, 12, 137-151. https://doi.org/10. 1111/j.1752-0606.1986.tb01631.x

Raytek, H. S., McCrady, B. S., Epstein, E. E., \& Hirsch, L. S. (1999). Therapeutic alliance and the retention of couples in conjoint alcoholism treatment. Addictive Behaviors, 24(3), 317-330. https:// doi.org/10.1016/S0306-4603(98)00085-9

Russell, K. A., Swift, J. K., Penix, E. A., \& Whipple, J. L. (2020). Client preferences for the personality characteristics of an ideal therapist. Counselling Psychology Quarterly. https://doi.org/10. 1080/09515070.2020.1733492

Schaffhuser, K., Wagner, J., Lüdtke, O., \& Allemand, M. (2014). Dyadic longitudinal interplay between personality and relationship satisfaction: A focus on neutoricism and self-esteem. Journal of Research in Personality, 53, 124-133. https://doi.org/10.1016/j. jrp.2014.08007

Sotero, L., Cunha, D., Da Silva, J. T., Escudero, V., \& Relvas, A. P. (2017). Building alliances with (In)voluntary clients: A study focused on therapists' observable behaviors. Family Process, 56(4), 36-58. https://doi.org/10.1111/famp.12265

Sotero, L., Moura-Ramos, M., Escudero, V., \& Relvas, A. P. (2018). When the family is opposed to coming to therapy: A study on outcomes and therapeutic alliance with involuntary and voluntary clients. Couple \& Family Psychology, 7(1), 47-61.

Tabachnick, B. G., \& Fidell, L. S. (2013). Using Multivariate Statistics (6th ed.). Pearson Education Limited.

Van der Steege, M. (2007). Intensieve Pedagogische Thuishulp komt tot wasdom. Naar een gouden standaard. Nederlands Jeugd Instituut.

Van Widenfelt, B. M., Treffers, P. D. A., De Beurs, E., Siebelink, B. M., $\&$ Koudijs, E. (2005). Translation and cross-cultural adaptation of assessment instruments used in psychological research with children and families. Clinical Child and Family Psychology Review, 8(2), 135-147. https://doi.org/10.1007/s10567-005-4752-1

Welmers van de Poll, M. J., \& Stams, G. J. J. M. (2019). Allianties in de ambulante gezinshulpverlening: Een observatieonderzoek naar de bijdrage van de hulpverlener. (Alliances in ambulatory family treatment an observation study on counsellors' contributions). Orthopedagogiek: Onderzoek en Praktijk, 58(9-10), 211-222.

Welmers-van de Poll, M. J., Roest, J. J., Van der Stouwe, T., Van den Akker, A. L., Stams, G. J. J. M., Escudero, V., Overbeek, G. J., \& De Swart, J. J. W. (2018). Alliance and treatment outcome in family-involved treatment for youth problems: A three-level metaanalysis. Clinical Child and Family Psychology Review, 41(2), 146-170. https://doi.org/10.1007/s10567-017-0249-y

Zilcha-Mano, S., Solomonov, N., Chui, H., McCarthy, K. S., Barret, M. S., \& Barber, J. P. (2015). Therapist-reported alliance: Is it really a predictor of outcome? Journal of Counseling Psychology, 62(4), 568-578. https://doi.org/10.1037/cou0000106

Zuroff, D. C., Kelly, A. C., Leybman, M. J., Blatt, S. J., \& Wampold, B. E. (2010). Between-therapist and within-therapist differences in the quality of the therapeutic relationship: Effects on maladjustment and self-critical perfectionism. Journal of Clinical Psychology, 66(7), 681-697. https://doi.org/10.1002/jclp/20683

Publisher's Note Springer Nature remains neutral with regard to jurisdictional claims in published maps and institutional affiliations. 